\title{
Evaluation of Teacher Education With a Focus on Its Effectiveness
}

\author{
Alena Opletalová \\ Correspondence: Alena Opletalová, Res. Asst., Palacký University Olomouc, Faculty of Education, The Institute of \\ Education and Social Studies, Czech.
}

Received: August 16, 2018

doi:10.11114/jets.v6i11a.3813
Accepted: October 26, $2018 \quad$ Online Published: November 29, 2018

URL: https://doi.org/10.11114/jets.v6i11a.3813

\begin{abstract}
The basis of the project is the current trend of lifelong learning and individual personality development, as well as the requirement to increase the quality of education programmes for Further Teacher Education (FTE). The research project has been carried out based on the findings of D. L. Kirkpatrick and his four-level model of training effectiveness evaluation. The main methods employed in the research are a questionnaire survey and standardized interviews with heads of schools sending their teachers to these programmes. The main objective of the research is to apply the method for FTE effectiveness evaluation at the Faculty of Education of Palacký University Olomouc and verify the method in practice. Tentative research objectives involve determining how the programme is evaluated by its graduates, analysing and interpreting the results of the research in FTE evaluation, and suggesting possible measures for further improvement and innovation regarding implementation of the particular programme.
\end{abstract}

Keywords: lifelong education, lifelong learning, further education of teachers, effectiveness

\section{Introduction}

A number of Czech universities currently have programmes for further education as a result of the current social needs. The status quo in further education practice may, however, not completely correspond to the actual needs of society regarding changing demands of the labour market. The current economic and social changes require further retraining-, subject-, and innovation-related studies focused on enhancing, updating and supplementing education or enabling the performance of a new occupation. They also require new approaches for acquisition of the necessary skills and competences, often key ones. Acquisition and cultivation of these are connected with personality development and thus even with education. According to European Commission policy must focus on quality. Quality: improving quality assurance, including monitoring and impact assessment, improving initial and continuing education of adult educators, and collecting the necessary data on needs to effectively target and design provision (European Commission, 2018).

The basis of the present research project is the current trend in lifelong learning and individual personality development, as well as the need to increase the quality of education programmes for the Further Teacher Education (FTE). While investment into the initial education of pedagogical staff is obviously taken for granted and its usefulness is not questioned, the views and attitudes towards financing of further education are not clear in practice. The effectiveness, i.e. the school's efficiency in the use of funding for FTE from the state budget, is assessed by the Czech School Inspectorate. This body also evaluates the implementation of the FTE plan, where specifically the monitoring and evaluation of FTE results may represent a weak point. According to instructions provided by the Ministry of Education, Youth and Sports No. 11 336/2001-25, Article 2, "the head of the school is responsible for the proper use of funds allocated for FTE". There is no clear answer as to the question of the actual practical use of FTE at schools, but there is undoubtedly some space for improvement in this area.

There are numerous educational courses and study programmes implemented at present at universities as well as at private education institutions. It is therefore important to conduct their evaluation, that is, determine their effectiveness, as not all of the educational activities have the required quality and provide so-called added value to graduates. The upcoming career code for teaching staff also involves, for instance, the question as to whether further self-education of teachers and the consequent increase in their qualifications would lead to greater benefits from the pedagogical perspective, as well as from the economic point of view, such as a higher income.

The aim of this study is to investigate the issue of FTE effectiveness evaluation. The main objective of the research is to apply the method for FTE effectiveness evaluation to the selected education programme implemented at the Faculty of Education of Palacký University Olomouc and verify the method in practice. The tentative research objectives involve 
determining how the FTE programme is evaluated by its graduates, analysing and interpreting the results of the research in FTE evaluation, and evaluating the research results with the aim of suggesting possible measures for further improvement and innovation regarding implementation of the particular programme. In order to fulfil these objectives, research in FTE effectiveness evaluation has been conducted.

The issue of determining education effectiveness is very significant (although not thoroughly elaborated in the available literature sources). "When determining the effectiveness of education and training, both the result and the process of education and training are assessed from the perspective of defined and expected goals, as well as from the viewpoint of return rate of costs on this process."(Skalka 1989, p. 243) In both practice and theory, effectiveness is often replaced with other terms, such as rationalization, optimization, evaluation, quality, etc. It is worth recalling that effectiveness involves efficiency of education and training by various means (e.g. didactic means, the proficiency level and abilities of the lecturer, organizational measures, etc.). Skalka defines effectiveness as "the relationship (i.e. the degree of harmony or disharmony) between objectives, results and costs of education and training. The evaluation of effectiveness is an objective, and at the same time a means, of increasing the effectiveness of education and training."

Assessment of pedagogical effectiveness of education and training may be simplified as assessment of the relationship between the objectives and the results of an educational process. In general, the effectiveness of the pedagogical process with adults may be assessed based on practical experience as well as findings from experiments and empirical verification of certain theories and principles, such as the theory of creativity, the theory of problem-based learning, or the theory of optimization (Opletalová, 2006). Such an investigation uses methods of pedagogical-psychological and pedagogical-sociological research, as well as general educational and training methods. In practice, however, determination of the pedagogical effectiveness of education faces a number of methodological problems, as stated for instance by Lazarová (2006, p. 40), who identifies the factors of effectiveness, circumstances and conditions under which effective teacher education can take place. She also defines and describes their interrelations and the ways in which they may influence the process.

Fundamental methodological problems in evaluating the effectiveness of further education have also been pointed out by Průcha (2002, p. 114), who emphasizes the importance of proving that further education actually leads to some changes in the work of teachers. According to Skalka (1989, p. 248), the objective of the analysis of pedagogical effectiveness is to determine the extent to which the results of a particular phase of education and training process correspond to or differ from the defined educational and training goals or hypotheses, theories, and principles being verified. On the basis of the findings and analyses as to which factors influence the pedagogical effectiveness positively and negatively, the conditions and means of optimization of the education and training process are established. The most frequent indicators of effectiveness are "the quantity and quality of changes occurring in the process of adult education and training. An education and training process is effective if it enables achieving maximal results with the minimal amount of time, effort and resources spent. Increasing the effectiveness of the education and training process means specifically optimization of relationships between the factors enhancing effectiveness - that is, increasing the influence of goals, content, methods, didactic means, teachers, educators, participants, the social climate, motivation, and the organization of the education and training process" Skalka (1989, p. 248).

The overall effectiveness of the education and training process with adults may be achieved particularly by optimizing all of the above-mentioned elements and factors. It is important that the effectiveness is always evaluated in a comprehensive manner. A number of the models of education evaluation available in the scholarly publications may be used for practical implementation, such as the approach of David Simmonds, A. H. Hamblin, Donald L. Kirkpatrick, and in Czech literature Kirkpatrick's model edited by J. Vodák, A. Kucharčíková and Hroník. Education assessment approaches can also be used of Bennet or Groundlund, N. E., Linn, R. L. The objective of the study is not, however, to analyse effectiveness in greater detail, but to apply the method for FTE effectiveness evaluation to the selected education programme, and present the related results.

\section{Method}

The research is conducted on the basis of findings of D. L. Kirkpatrick and his four-level model of training effectiveness evaluation. The primary methods are a questionnaire survey of teachers who have completed a programme for further education, and standardized interviews with heads of schools sending their teachers to these programmes. As already stated in the theoretical part of the study, investigation and measurement of training effectiveness in teaching practice is considerably complicated if objectivity is to be guaranteed. When determining effectiveness, objectivity may be ensured by the complexity and systemic analysis of all phases of the education and training process (i.e. preparation, process and results) using various methods and techniques. These challenges were borne in mind when conducting the research.

It is apparent that investigation, i.e. determination of effectiveness of FTE, brings with it a number of methodological 
challenges. These may involve the following methodological issues that need to be tackled when evaluating effectiveness:

- How much time should pass after the education has been completed?

- How to eliminate the subjectivity of training evaluation by the participants?

- Have any changes been made to the work of teachers and have they been caused exclusively by education?

- Can we state that the change triggered by education will have a lasting character in the work of teachers and will not return over time to the state before the change occurred?

Based on the general research objectives, the following hypotheses were formulated for research investigation:

$\mathrm{H} 1$ - There are differences in the evaluation of educational activities and its individual aspects among graduates in the individual years of study.

$\mathrm{H} 2$ - There are differences in the level of knowledge and skills before and after the educational activity.

H3 - Most graduates of educational activity claim to be applying the knowledge and experience acquired during their studies to their work.

H4 - Due to the fact that teachers have taken part in education, the heads of schools can see the benefits with regard to school activities.

The above stated hypotheses and their content are consistent with the individual levels of D. L. Kirkpatrick's four-level training evaluation model, so that the outputs of the investigation can always be comprehensively evaluated at a specific level. It is certainly desirable to operationalize these hypotheses in order to determine tentative, i.e. specific, hypotheses.

The first level of evaluation (reaction), aimed at evaluating the reactions of study graduates, investigates how graduates of the educational activities felt and whether they perceived its benefits for themselves as individuals. This level of evaluation investigates information regarding the participants' attitudes to learning. These are the individuals' reactions to experiences from education, their perception of the usefulness of the study, lecturers, content, organization, etc. (American Evaluation Association, 2018). If the participants' reaction is positive, the probability of application of acquired knowledge in practice in significantly higher. The research method for the first level was a questionnaire survey. The questionnaires were distributed to participants in person at the time of graduation, that is, immediately after completion of the final exam. The evaluation questionnaire used for evaluation of the reactions of graduates of the educational activity was designed in accordance with general rules (Chráska 2007, p. 169-171) and divided into five sections (study content, cooperation with teachers, study support, study organization, and final evaluation of study). It consisted of fifteen questions related to evaluation of studies concerning the above stated aspects.

The second level of evaluation (learning) of FTE measures the effectiveness of the process of transfer of knowledge and skills to the participants of the educational activity. This involves investigating what the participants have learned during their studies, how they acquired the new knowledge and skills and what changes to their attitudes have occurred. Investigation on this level does not consider whether the things they have learned are relevant to their work and whether these help them enhance their performance. The method for investigation of the increase in knowledge was once again a questionnaire survey. A test of knowledge, before and after the educational activity, was initially intended. This method was discarded, however, as one scarcely reflecting the investigated issue, as the research was conducted with a two-year study programme, where the students are presumed to be entering into the study possessing almost no knowledge which is to be acquired over the course of studies. An alternative investigation method could be a structured interview, but with regard to the amount of participants it is not all that efficient either. The questionnaire for research in the second level of the effectiveness evaluation is divided into two sections: the first part addresses the situation before the studies (No. 1, 2, and 3), while the second section focuses on the situation after completion of the studies (No. 1, 2, 3, 4, 5, and 6). The questionnaire items are formulated as trichotomic, semi-closed and open questions.

The effectiveness evaluation of the implemented education on the third level of the model monitors the impact of studying on the performance of individuals in their work (behaviour). This involves determining the extent to which the graduates apply at work the knowledge and experience acquired during their studies. The investigation of the impact of the study on the individual performance employs a questionnaire and structured interviews with the superiors of study participants, and involve estimates of benefits of the educational activity, the level of qualification acquired, estimates of the worker's performance, etc. The most effective method for evaluation once again seems to be the questionnaire survey. With regards to the investigated area, it has to be conducted with a certain time lag from the graduation from the educational activity. As stated in scholarly literature, the most convenient period for interviews or questionnaires is four to six months after the completion of the studies (Vodák and Kucharčíková 2007, p. 132). The research questionnaire 
was distributed to graduates in an electronic form six months after completion of the study. The questionnaire, designed for evaluation of the educational activity on the third level, consists of six items: these include trichotomic, semi-closed, open and scale questions.

Evaluation on the fourth level deals with the impact (results) of the educational activity on the effectiveness of the school (i.e. the entire organizational unit) and investigates whether the school regards it as a cost-efficient activity. Investigation of the impact of the educational activity on the effectiveness of an institution (school) may employ a wide range of methods. These include structured interviews with the school management, assessment of the benefits conducted by the school management, an analysis of trends and impacts, implementation of management models, etc. From the perspective of feasibility, their utilization is rather limited in the context of the other methods and the research sample used. This is why the research method used for the study involved pilot interviews with a diverse sample of participants, i.e. heads of schools (or school management) focused on identification of benefits for the school. The questions to be asked in the interview were fixed and focused particularly on school activities, not on the individual's teaching. There is a risk that the school management may be too distant from the teacher's (that is, the study participant's) direct activities to be capable of observing the direct impact on teaching. The reason for this is that the school management may not be interested in the improvement of skills of the individual teachers, but rather in the way their performance contributes to improvement in the performance of the entire school. The interview addressed school activities and subsequently sought out possible connections with the educational activity completed by the teacher.

The choice of the research sample is deliberate with regard to the current situation. With the aim of constructing a method for evaluation of FTE effectiveness at the Faculty of Education of Palacký University Olomouc, the research sample comprised graduates of FTE programmes implemented at this faculty. Implementation of FTE programmes is ensured organizationally, administratively and economically by the Centre for Lifelong Education at the Faculty of Education of Palacký University Olomouc. The empirical research was conducted with a sample consisting of graduates of one selected study programme. It was the intention of the author to select a study programme implemented in accordance with Decree No. 317/2005 Coll. on Further Education of Teachers, Section 2 (Study in Teaching Sciences), particularly the Pedagogical Study of Teachers of General or Vocational Subjects at Secondary Schools (hereinafter pedagogical study). A total of 291 graduates participated in the questionnaire survey. The interviews involved participants from the schools of ten graduates.

\section{Findings}

Data obtained in the questionnaire survey was processed in two phases in the following way. First, the individual items of the questionnaire results were processed and tables were created analysing the absolute and relative frequencies for the individual items. The above-mentioned data was subsequently processed with the Statistika CZ 6.0 software, using Pearson Chi-Square and Kruskal-Wallis nonparametric tests. The testing was conducted with the significance level 0.05.

Based on an evaluation of the research results, i.e. the obtained statistically significant differences, it was impossible to confirm or reject unequivocally the validity of hypothesis No. 1 (H1), which was based on the first level of FTE effectiveness evaluation. It is, however, possible to adopt the following conclusions. Differences in the evaluation of the educational activity occur among graduates in the individual years of study as to the form of communication, cooperation with the study organizer, study support (for General Pedagogy, General Didactics, and Child and Youth Biology) and study content (for General Pedagogy and Psychology, an elective course, and Child and Youth Biology). There are no differences in evaluation of the educational activity as to the overall study evaluation, the number of consultation sessions, the number and extent of distance assignments, comments on the study organization, cooperation with teachers, study support (for General Psychology, School Management, an elective course, and Subject Didactics), and study content (for General Didactics, School Management, Subject Didactics, and Practical Pedagogical Training).

Following a thorough analysis and interpretation of the results obtained from FTE effectiveness evaluation on the second, third and fourth levels, the validity of the remaining three hypotheses was confirmed:

$\mathrm{H} 2$ - There are differences in the level of knowledge and skills before and after the educational activity.

$\mathrm{H} 3$ - The majority of graduates of the educational activity claim to be applying the knowledge and experience acquired during their studies in their work.

H4 - The heads of schools perceive benefits to school activities resulting from the education undertaken by their teachers.

In order to summarize the research results and draw tentative conclusions, the preliminary results of the research and their interpretations are presented below.

This involved an analysis of statistically significant differences detected in evaluation of pedagogical study on the first level. The evaluation on the first level, i.e. the assessment of reactions, analysed the attitudes of the participants towards 
the undertaken pedagogical study, particularly in the last four years of study. Statistical processing of evaluation questionnaires focused on evaluation of study content, cooperation with teachers, study support and study organization resulted in the following statistically significant differences in evaluation of the individual aspects of study among the four years of graduates.

The form of communication

When evaluating the form of communication, a statistically significant difference was detected among the individual years of the graduates. This may be interpreted according to the individual values of the relative frequencies in the respective years. It is apparent that a more significant difference in the answers when e-learning was first incorporated into the studies. It is therefore apparent that the difference in evaluation was caused by adaptation of the study to a new form of communication. In general, values exceeding $90 \%$ suggest that almost all the graduates were satisfied with the study implemented in the distance education.

Cooperation with the study organizer

The greatest difference in evaluation of the study organization occurs in the last period where evaluation with mark 1 is less frequent in contrast to more frequent evaluation with mark 2. Based on the participants' comments stated in open answers regarding this aspect, it can be assumed that study participants would welcome, for example, a greater amount of study support, materials and information in an electronic form, strict adherence to the given schedule, closer contact, and division into groups of those already teaching and those who do not possess any experience with pedagogical work as yet.

Table 1. Evaluation of study organization on a scale 1-5 (1= best $-5=$ worst $)(\%)$

\begin{tabular}{cccccc}
\hline $\begin{array}{c}\text { Evaluation on a } \\
\text { scale } 1-5\end{array}$ & $\begin{array}{c}\text { Group } \\
1\end{array}$ & $\begin{array}{c}\text { Group } \\
2\end{array}$ & $\begin{array}{c}\text { Group } \\
3\end{array}$ & $\begin{array}{c}\text { Group } \\
4\end{array}$ & Total \\
\hline 1 & 1,1 & 0 & 0 & 4,1 & 1,3 \\
\hline 2 & 77,5 & 73,4 & 80,9 & 55,4 & 71,8 \\
\hline 3 & 16,9 & 23,3 & 17,6 & 27 & 21,2 \\
\hline 4 & 3,4 & 3,3 & 0 & 6,8 & 3,4 \\
\hline 5 & 1,1 & 0 & 1,5 & 6,7 & 2,3 \\
\hline
\end{tabular}

Note: Mark 5 was not used in any of the questionnaires.

Study support (for courses of General Pedagogy, General Didactics, and Child and Youth Biology)

The individual groups of graduates differed in their evaluation of the best study support material in courses of General Pedagogy and General Didactics. It is apparent from the tables in the attachments to the dissertation that in the last year, the evaluation of these study support materials was significantly higher and they are classified as the best ones. The reason may be innovation made to both the form and the content of study support for these courses.

Study content (for General Pedagogy and Psychology, an elective course, and Child and Youth Biology)

Based on the values of relative frequencies for the item evaluating the content of courses from the perspective of its usefulness, applicability and attractiveness, the above-mentioned courses (where a statistically significant difference in evaluation occurred) show a rather deteriorating evaluation over time. It would apparently be suitable to update and innovate these courses with regard to their content, to include a greater amount of practical exercises and demonstrations, and in general to create a closer link between theory and practice. These are comments expressed in open answers within the questionnaire survey.

\section{An overview of the results of tentative hypotheses on the second level of evaluation}

The aim of FTE effectiveness evaluation on the second level is to determine the effectiveness of the process of knowledge and skill transfer to the participant of the educational activity. It involves determining whether the participants learned anything, what specifically they learned as a result of education, how they acquired new knowledge or skills, and possibly also how their attitudes changed. These issues were the focus of the above defined tentative hypotheses. Their validity was confirmed by the research, thus also confirming the validity of hypothesis No. 2 (H2). Based on the previous analysis of questionnaire survey results, all of the following tentative factual hypotheses are confirmed:

$\mathrm{H} 2$ a) The expected education benefits correspond to the actually acquired knowledge and skills.

$\mathrm{H} 2$ b) The group of study participants includes a greater amount of those who have not yet completed any education 
focused on teacher training yet, compared to those who have already completed some kind of study focused on pedagogy.

$\mathrm{H} 2 \mathrm{c}$ ) The majority of participants in the pedagogical teacher training consider the enhancement of their qualifications to be the main reason for participating in the training, so that they can work as teachers.

H2 d) Graduates of pedagogical study will be motivated to seek improvement in various areas related to the teaching profession.

H2 e) Graduates of pedagogical study will seek further education in all main areas of their pedagogical profession.

$\mathrm{H} 2 \mathrm{f}$ ) With respect to the clearly defined profile of the graduate of the pedagogical study and the previous expectations of the participants, the majority of participants will not notice any unexpected benefits of graduation.

$\mathrm{H} 2 \mathrm{~g}$ ) Over the course of the studies, the participants acquire on average more than $50 \%$ new information.

$\mathrm{H} 2 \mathrm{~h}$ ) Following the completion of their education, the majority of the participants will be convinced that their decision to work as teachers was appropriate.

\section{An overview of the evaluation results on the third level: the impact of studies on the individual's performance at work}

The third level of FTE effectiveness evaluation monitors primarily the changes in behaviour and actions of participants of education as a consequence of the educational activity. The author considers this part to be the key one for assessment, because its aim is to detect whether graduation of the educational activity has a positive impact on the teachers' performance in their subsequent work. The results obtained from the questionnaire survey may be summarized as follows:

- $\quad 75.9 \%$ of graduates of the pedagogical study apply the acquired knowledge and skills in their teaching;

- in their work, the teachers especially use new teaching methods, presentation and communication skills, and motivational elements; only $4 \%$ of participants do not use any knowledge acquired in the pedagogical study;

- $69 \%$ of participants believe that doing the studies was necessary for their work as a teacher;

- as many as $50 \%$ cannot state whether their students have noticed any positive change in lessons as a result of their graduation in pedagogical study. Another $39.3 \%$ of teachers believe that their students have noticed positive changes in lessons as a result of their graduation in pedagogical studies;

- undertaking pedagogical studies helped the teachers in practice particularly in conducting their teaching in a more professional way, and using new teaching methods, findings in subject-related preparation for lessons, and findings in child and youth biology;

- with regard to the applicability of the individual courses in practice, findings from general didactics were perceived as the most useful, while those from child and youth biology were considered the least useful.

Based on the above presented analysis of the results of the investigation in the impact of the study on the individuals' performance in their work, the presumed statement, i.e. hypothesis No. $3(\mathrm{H} 3)$, may be regarded as confirmed.

An overview of the evaluation results on the fourth level: the impact of studies on performance of the entire institution

From the perspective of the institution (the employer, the school), it is desirable not only to recognize a certain positive impact of the completed education, but to assess the particular influence of this change on school activities.

The following conclusions may be drawn from an analysis of the results obtained from the structured interviews:

- the impact of the educational activity on the school's culture is regarded as positive by school management;

- school management have noticed a positive motivation in the pedagogical work of the teachers who have undertaken the educational activity;

- school management estimates that after graduation from the studies the performance of their teachers increased on average by $20 \%$;

- school management reports a personal approach and behaviour of their teachers in contact with students;

- having graduated in pedagogical studies, the teachers participate in various extra-curricular activities at school (e.g. managerial, creative, or pedagogical-didactic); 
- $\quad$ some of the teachers have been appointed to new positions at schools (such as a class teacher, the chair of a subject committee, or an educational counsellor);

- the teachers often introduce new ideas for innovation in school activities (beyond the scope of their teaching).

The above listed results, of the analysis of information obtained from structured interviews, indicate that representatives of the schools' top managements have noticed the above described benefits which may be attributed to their teachers' graduation in FTE. The statement formulated in hypothesis No. 4 (H4) may thus be regarded as confirmed.

\section{Results, Conclusions and Recommendations}

This section will clarify the findings obtained in the empirical research and compare them to the theoretical findings and results of other empirical research projects. It will also present suggestions for further research and discuss the limitations of the present empirical research.

With regards to the needs of the organizer of the pedagogical study, as well as of other participants (such as the study guarantor, teachers of the respective courses, faculty management, etc.), the author believes it is appropriate and desirable to also present ideas, recommendations and measures that may be applied in further implementation of these studies. These suggestions are derived from investigation on all levels of FTE effectiveness evaluation conducted within the research.

Suggestions for further activities, leading to the enhanced effectiveness of the implemented pedagogical study, may be briefly summarized as follows:

- update and innovation of the content of certain courses (e.g. General Pedagogy, General Psychology, elective courses, and Child and Youth Biology), in particular incorporation of a greater amount of practical exercises and demonstrations and a greater link between theory and practice (even increasing if needed the amount of lessons in some practical courses);

- development of new study support materials for certain courses (e.g. Child and Youth Biology) that would reflect to a greater extent the requirements for independent distance learning. All study support including supplementary study materials should be available in an electronic form via the e-learning platform LMS;

- consistent use of a unified form of communication within LMS by all tutors (i.e. teachers in the distance study programme), the study administrator, and participants;

- providing a more active and personal approach in communication on the part of the study organizer, ensuring strict adherence to the given schedule, and division of participants into groups of teachers with experience in teaching practice and those who do not yet possess any experience in the field of pedagogical work.

On the societal level, it is appropriate to perceive FTE as a significant social activity. It is becoming an important political and socio-cultural topic as well as an individual issue relevant to each teacher. It also concerns various levels of educational policy and is becoming part of the personal development and career progression of an individual undertaking education. It is apparent that the attention paid to further education and its support are reflected in the quality of teachers' work with youth, and as such, this area should not be neglected. Teachers participating in further education and applying the acquired knowledge and skills in order to enhance the quality of their pedagogical work contribute to the development of the entire school. In order to achieve the expected long-term effect, further education must be provided with high-quality and effectiveness. It is also desirable to purposefully use both the public and private funding invested in the educational activity by its participants. From this perspective, there is also a need to deal with the effectiveness of further education and the impact of this education on school practices.

As already stated, investigation and measurement of education effectiveness in pedagogical practice is considerably complicated if objectivity is to be guaranteed. When determining effectiveness, objectivity may be ensured by the complexity and systemic analysis of all phases of the education and training process (i.e. preparation, process, and results) using various methods and techniques. These challenges were borne in mind when conducting the research. The main issue for evaluation of education effectiveness is that the impact of the educational activity occurs in practice with a certain time lag. It is also impossible to strictly separate the effects of the individual influences causing the particular changes. Although there may arise numerous reservations about the measurement of satisfaction or the relation of the educational activity to work performance, both of these measurements need to be conducted. To eliminate imperfections in the available measurement tools, there is a need to combine them appropriately so that they complement each other that is, using evaluations from multiple levels of perception, as done in this study using Kirkpatrick's model and its application to a particular educational activity. 
In conclusion, it is unfortunately impossible to unequivocally state whether the investigated educational activity is effective or not. The author has come to the conclusion that it is more beneficial and useful to formulate tentative statements or conclusions on the individual levels of effectiveness. The author assumes that FTE effectiveness evaluation will continue to rank among topical and discussed issues within the field of education, as the topic is relevant and useful to all participants in the educational activity.

\section{References}

American Evaluation Association (2018). Guiding Principles for Evaluators. https://www.eval.org/p/cm/ld/fid=51.

Bennet, J. (2003). Evaluation: A Multi-method Evaluation. Continuum International Publishing Group.

European Commission (2018). Education and Training 2020. http://ec.europa.eu/education/policy/strategic-framework_cs.

Groundlund, N. E., \& Linn, R. L. (1990). Measurement and Evaluation in Teaching. 6th edition. New York: Macmillan Publishing.

Hamblin, A. C. (1974). Evaluation and Control of Training. 1st edition. London: McGraw-Hill.

Hroník, F. (2007). Rozvoj a vzdělávání pracovnikủ. Praha: Grada Publishing. 178.

Kirkpatrick, D. L. (1991). Evaluating Training Programmes: The Four Levels. In: Lernpsychologie des Erwachsesnealters, Transfer-Stiftung für markwirthschaftsorcentierte Kaderschulung. St. Allen.

Lazarová, B. et al. (2006). Cesty dalšího vzdělávání učitelů. Brno: Paido.

Lazarová, B., \& Prokopová, A. (2004). Učitelé a jejich další vzdělávání. K některým psychologickým aspektům.Pedagogika, 54 (4), p. 261-273.

Ministry of Education, Youth and Sports No. 317/2005 Coll. on Further Education of Teachers, Section 2.

Ministry of Education, Youth and Sports. No. 11 336/2001-25, Article 2. www.msmt.cz/file/38061_1_1/

Opletalová, A. (2006). Pedagogická efektivita vzdělávání v rámci „Pedagogického studia učitelư“. In SCHOLA 2006. Kvalita výchovy a vzdělávania. Sborník příspěvků ze 7. mezinárodní vědecké konference. Bratislava: PdF.

Průcha, J. (2002) Učitel. Současné poznatky o profesi. Praha: Portál.

Skalka, J. et al. (1989). Základy pedagogiky dospělých. Praha: SPN, p. 249.

Vodák, J., \& Kucharčíková, A. (2007). Efektivni vzdělávání zaměstnanců. Praha: Grada Publishing. p. 123.

\section{Copyrights}

Copyright for this article is retained by the author(s), with first publication rights granted to the journal.

This is an open-access article distributed under the terms and conditions of the Creative Commons Attribution license which permits unrestricted use, distribution, and reproduction in any medium, provided the original work is properly cited. 